Saudi Journal of Medicine

Abbreviated Key Title: Saudi J Med ISSN 2518-3389 (Print) |ISSN 2518-3397 (Online) Scholars Middle East Publishers, Dubai, United Arab Emirates

Journal homepage: https://saudijournals.com/sjm

Original Research Article

\title{
Metabolic Effect of Vitamin C on Rats Exposed To Inhaled Marijuana
}

\section{Udokang Nsikak Ephraim ${ }^{1 *}$, Udom Utibe Godwin ${ }^{1}$, Aribo Ekpe Okpata ${ }^{2}$}

${ }^{1}$ Department of Physiology, University of Uyo, Uyo, Nigeria

${ }^{2}$ Department of Physiology, College of Medical Science, University of Calabar, Nigeria

DOI: $10.36348 /$ sjm.2020.v05i01.013 $\quad$ | Received: 20.01.2020 | Accepted: 27.01 .2020 | Published: 30.01 .2020

*Corresponding author: Udokang Nsikak Ephraim

\section{Abstract}

The antifertility potency of Marijuana had been revealed in our recent study. Hence, investigating its effect on other body systems became necessary. This study was setup to determine the effects of inhaled marijuana and Vitamin $\mathrm{C}$ on serum lipids and serum proteins of male rats using the following parameters; Total Cholesterol level, Triglycerides level, High density Lipoprotein level, Low density Lipoprotein level, Albumin level, Total Bilirubin level, Direct Bilirubin level and Total Protein level. This study was carried out with a total of forty (40) male wistar rats randomly divided into four groups of ten (10) rats per group. Group 1 was the control and was treated with distilled water, group 2 was the low dose group (exposed to marijuana smoke for 5 minutes daily), group 3 was the high dose group (exposed to marijuana smoke for 10 minutes daily) and group 4 was the high dose + vitamin $C$ group (exposed to marijuana smoke for 10 minutes and orally gavaged with vitamin $\mathrm{C}$ at $2.8 \mathrm{mg} / \mathrm{kg}$ body weight daily). The animals were sacrificed on the $29^{\text {th }}$ day and blood was collected by cardiac puncture into plain bottles. The collected blood was allowed to clot and centrifuged at $300 \mathrm{rev}$ per minutes for 20mins. The serum was collected with the aid of a micropipette for the biochemical analysis of lipid profile and serum protein according to George, 2009 and Bjorsten et al., 2007. The results were as follows; Serum albumin and Total bilirubin levels were significantly decreasing $(p<0.05)$ down the groups. Direct bilirubin level was significantly increased $(\mathrm{p}<0.05)$ in the low dose marijuana $(\mathrm{LMJ})$ treated group when compared with the control group and was significantly decreased in the high dose marijuana + vitamin C (HMJ+Vit C) treated groups when compared with control and high dose marijuana (HMJ) treated groups respectively. Total protein was significantly decreased $(\mathrm{p}<0.05)$ in the high dose Marijuana + vitamin $\mathrm{C}(\mathrm{HMJ}+\mathrm{Vit} \mathrm{C})$ treated groups when compared with control group and within the other groups. Total cholesterol levels was significantly decreased $(\mathrm{p}<0.05)$ in the high dose Marijuana + vitamin $\mathrm{C}(\mathrm{HMJ}+\mathrm{Vit} \mathrm{C})$ treated groups when compared with control group. High density lipoprotein levels was significantly decreased $(\mathrm{p}<0.05)$ in the high dose Marijuana + vitamin $\mathrm{C}(\mathrm{HMJ}+\mathrm{Vit} \mathrm{C})$ treated groups when compared with control group. Triglycerides level was not significantly different in the low dose Marijuana (LMJ) treated group and high dose Marijuana + vitamin C (HMJ+Vit C) treated groups when compared with control group and within the groups. Low density lipoprotein level was significantly increased $(\mathrm{p}<0.05)$ in the high Marijuana + vitamin C $(\mathrm{HMJ}+\mathrm{Vit} \mathrm{C})$ treated groups when compared with control group. This study has shown that inhaled Marijuana negatively affected various liver metabolic pathways leading to decline in albumin levels; elevated Bilirubin and lipid levels.Coadministration of oral Vitamin $\mathrm{C}$ was found to lower serum Bilirubin levels. Levels of total Cholesterol, High Density Lipoproteins and Tryglycerides were also lowered in rats treated with Vitamin C. It is possible that the use of Vitamin C may be beneficial in individuals at risk of cardiovascular diseases.

Keywords: Metabolic effect, Marijuana, Vitamin C, Serum Lipid, Serum Protein.

Copyright @ 2020: This is an open-access article distributed under the terms of the Creative Commons Attribution license which permits unrestricted use, distribution, and reproduction in any medium for non-commercial use (NonCommercial, or CC-BY-NC) provided the original author and source are credited.

\section{INTRODUCTION}

Marijuana use is expected to increase tremendously as it has been decriminalized in more countries today. Together with its addictive potential which enhances the long term use, its use poses serious threat on the body systems.
In our recent works [1, 2], it has been observed that Marijuana (Cannabis sativa) poses serious threat on the reproductive system. The observed antifertility effects include decrease in testicular weight, testicular damage, seminal defects, fluctuations in sex hormonal levels, etc. Having observed these effects, it becomes pertinent to assess the effects in which this drug may have on metabolism. 
Marijuana contains many chemicals, with $\Delta 9$ tetrahydrocannabinol $(\triangle 9-\mathrm{THC})$ and Cannabidiol (CBD) being the main ingredients of Cannabis sativa plant and having distinct symptomatic and behavioral effect [3].

Two cannabinoid receptor systems have been discovered, cannabinoid 1 receptor (CB1R) in the brain specific for $\triangle 9$-THC [4] and cannabinoid 2 receptor (CB2R) discovered by [5].

CB1Rs are mainly in the brain, particularly in the substantia nigra, the basal ganglia, limbic system, hippocampus and cerebellum, but are also expressed in the peripheral nervous system, liver, thyroid, uterus, bones and testicular tissue [6-8]. CB2Rs are mostly expressed in immune cells, spleen and the gastrointestinal system, and to some extent in the brain and peripheral nervous system [8, 9].

In metabolic processes, the liver plays a central role, being involved in fat metabolism, drug metabolism and detoxification, enzyme synthesis and function, etc. With this perception and the fact that marijuana receptors are observed to be located in the liver and the gastrointestinal tract, therefore individuals with chronic marijuana use are at risk of metabolic health defect. Also, having observed detrimental effect in the reproductive system [1]; and metabolism have been linked with reproduction, it is as well possible that marijuana use would alter metabolic processes.

\section{Purpose of the study}

This study was setup to determine the

Effects of inhaled marijuana on serum lipids and serum proteins of male rats using the following parameters;

a) Serum Lipid Profile

- Total Cholesterol level

- Triglycerides level

- High density Lipoprotein level

- Low density Lipoprotein level

b) Serum Proteins

- Albumin level

- Total Bilirubin level

- Direct Bilirubin level

- Total Protein level

Potency of ascorbic acid in ameliorating the inhaled marijuana effects.

\section{Significance of the study}

Having observed antifertility effects of marijuana in our recent study, it became the rationale and an important subject matter to examine the effect in other systems and the metabolic system turn out to be our focus.

\section{METHODOLOGY \\ Drugs and Animal Collection \\ Marijuana}

An approval and sample of cannabis sativa was gotten from The State Command, National Drug and Law Enforcement Agency (NDLEA), Akwa Ibom State Command, Uyo, for the study.

\section{Ascorbic Acid (Vitamin c)}

A packet of Emzor 100mg vitamin c tablets was bought from Leadsons pharmacy in Uyo, Akwa Ibom state.

\section{Animals}

Prepubertal rats of the Wistar strain (60-80g) were obtained from the animal house of the faculty of Basic Medical Sciences, University of Uyo and kept in wooden cages of $50 \times 30 \mathrm{~cm}$ dimension in a wellventilated section of the same animal house for acclimatisation. The animals were fed with rat chow (vital feed) and were allowed free access to drinking water while the experiment lasted.

\section{Experimental Design}

A total of forty (40) prepubertal male albino rats were randomly designed into four (4) groups of ten (10) animals per group with group 1 as control group. Group 2, 3 and 4 served as experimental groups. Group 2 rats (low dose cannabis) were exposed to cannabis smoke through inhalation for 5 minutes a day. Group 3 rats (high dose cannabis) were exposed to cannabis smoke through inhalation for 10minutes a day. Group 4 (high dose cannabis + ascorbic acid) was exposed to cannabis smoke through inhalation for 10minutes a day and ascorbic acid. Group 1 (control group) were given distilled water and feed throughout the experimental days.

\section{Administration \\ Marijuana}

Daily, animals from group 2, 3 and 4 were exposed to marijuana smoke. This was done by putting $1 \mathrm{~g}$ of the cannabis rolled with rizla rolling paper in a red-hot charcoal in a stainless plate and placing it in an airtight smoking chamber with 10rats per smoking session for five (5) minutes. The procedure was repeated for the group 3 and 4 for another five (5) minutes each day, making the total time of exposure of this two groups (3 and 4) to be ten (10) minutes each day. The air-tight smoking chamber was made from polythene plastic cage of $60 \mathrm{~cm} \times 50 \mathrm{~cm} \times 40 \mathrm{~cm}$ dimension.

\section{Ascorbic Acid}

After the cannabis smoke exposure, the group 4 rats were orally gavaged with $2.8 \mathrm{mg} / \mathrm{kg}$ body weight of ascorbic acid. 


\section{Sample Collection and Analysis}

Sample Collection

After 28 days of administration, the rats were anaesthetized using chloroform and sacrificed. Blood was collected by cardiac puncture into plain bottles. Approval was gotten from the Local Research Ethical Committee of the University of Uyo, Uyo, Akwa Ibom State, Nigeria.

\section{Biochemical Analysis}

The collected blood was allowed to clot and centrifuged at $300 \mathrm{rev}$ per minutes for $20 \mathrm{mins}$. The serum was collected with the aid of a micropipette for lipid profile and serum protein levels analysis.

\section{Lipid Profile}

The plasma concentration of TC, TG, HDLcholesterol and LDL-cholesterol were measured using spectrophotometric methods. Laboratory kit reagents (Randox Laboratory Ltd, UK) were used for all biochemical analysis and their absorbance were read using a UV-Vis spectrophotometer (DREL 3000 $\mathrm{HACH})$.

\section{Serum Protein}

a) Estimation of serum total protein: The biuret reaction method was used for serum protein measurement [10]. The intensity of the violet color was measured using a DRE 3000 $\mathrm{HACH}$ spectrophotometer and is proportional to the concentration of protein [11].

b) Estimation of serum albumin: Albumin was measured by a dye-binding technique that utilizes the ability of albumin to form a stable complex with bromocresol green dye [10]. Estimation of albumin level (g/dl) was obtained using a DRE $3000 \mathrm{HACH}$ spectrophotometer.

c) Estimation of serum globulin: The total globulin fraction was determined by subtracting the albumin fraction from the total protein fraction.

\section{Statistical Analysis}

Data obtained were analyzed using Mean, Standard Error of Mean, Analysis of Variance and and Tukey post hoc test followed by Duncan's test which was used to determine the direction of significance. The level of Serum Protein and Lipid Profile were reported in the form mean \pm SEM and statistical significance was established at 0.05 level of significance with $\mathrm{p}<0.05$ signifying significance. Data were analyzed using the Statistical Package for Social Sciences (SPSS version 22.0) and GraphPad Prism 5.0.

\section{RESULT}

Effects of Inhaled Marijuana and Vitamin $C$ on Serum Albumin Levels in Male Wistar Rats

Serum albumin was significantly decreased $(\mathrm{p}<0.05)$ in the high dose Marijuana + vitamin $\mathrm{C}$
$(\mathrm{HMJ}+\mathrm{Vit} \mathrm{C})$ treated group when compared with the control group. An intermediary Serum albumin level between the Marijuana + vitamin C (HMJ+Vit C) treated group and the control group was recorded by the low dose marijuana (LMJ) and high dose marijuana (HMJ) treated groups (Figure-1).

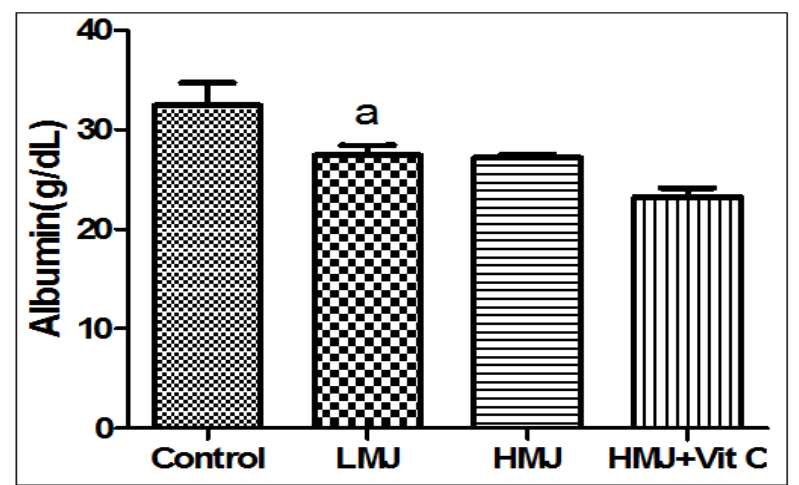

Fig-1: Graphical comparison of Serum albumin level in male Wistar rats following the administration of marijuana and vitamin $\mathrm{C}$ in the treated groups with the control group. Columns represent mean \pm SEM. $n=10{ }^{a} p<0.05$ when compared with the control group. Analysis was based on one way analysis of variance (ANOVA) and Tukey post hoc test

Key: Control- Control group; LMJ-Low dose Marijuana group; HMJ-High dose Marijuana group; HMJ+Vit C- High dose Marijuana + Vitamin C

\section{Effects of Inhaled Marijuana and vitamin $C$ on total} Bilirubin Levels in Male Wistar Rats

Total bilirubin level was significantly decreased $(\mathrm{p}<0.05)$ in the high dose marijuana $(\mathrm{HMJ})$ treated group when compared with the control group and low dose Marijuana (LMJ) treated groups respectively. Total bilirubin level was even more significantly decreased in the high dose Marijuana + vitamin C (HMJ+Vit C) treated groups when compared with control group, low dose Marijuana (LMJ) and high dose Marijuana (HMJ) treated groups respectively (Figure-2).

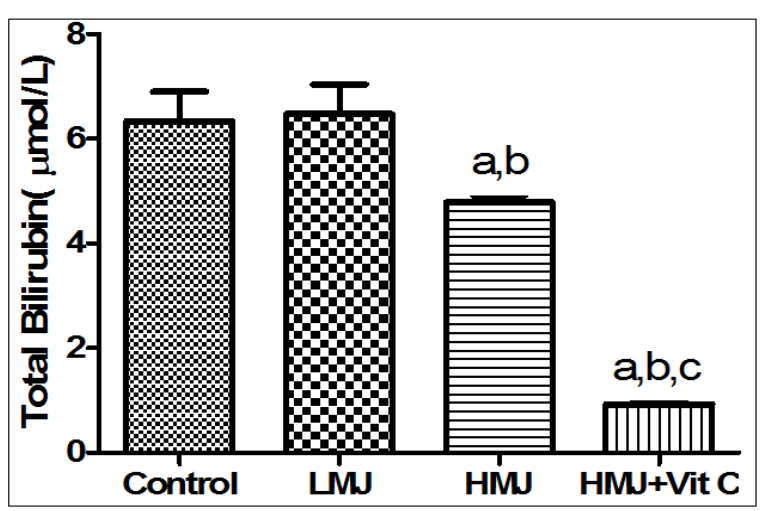

Fig-2: Graphical comparison of Total bilirubin level in male Wistar rats following the administration of marijuana and vitamin $\mathrm{C}$ in the treated groups with the control group. Columns represent mean \pm SEM. $n=10 .{ }^{a} p<0.05$ when compared with the control group. ${ }^{b} p<0.05$ when compared with the low dose marijuana (LMJ) treated group. ${ }^{c} \mathbf{p}<0.05$ when compared with the high dose marijuana (HMJ) treated group. Analysis was based on one way analysis of variance (ANOVA) and Tukey post hoc test 
Key: Control- Control group; LMJ-Low dose Marijuana group; HMJ-High dose Marijuana group; HMJ+Vit C- High dose Marijuana + Vitamin C

Effects of Inhaled Marijuana smoke and vitamin C on direct bilirubin levels in male Wistar rats

Direct bilirubin level was significantly increased $(\mathrm{p}<0.05)$ in the low dose marijuana $(\mathrm{LMJ})$ treated group when compared with the control group. Direct bilirubin level was significantly decreased in the high dose marijuana + vitamin $\mathrm{C}(\mathrm{HMJ}+\mathrm{Vit} \mathrm{C})$ treated groups when compared with control and high dose marijuana (HMJ) treated groups respectively (Figure-3).

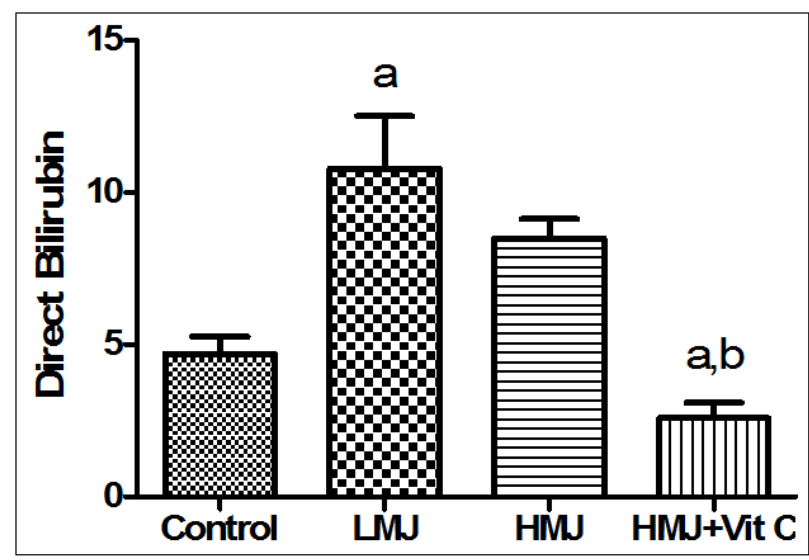

Fig-3: Graphical comparison of Direct bilirubin level in male Wistar rats following administration of Marijuana and vitamin C in the treated groups with the control group. Columns represent mean \pm SEM. $n=10$. ${ }^{a} p<0.05$ when compared with the control group. ${ }^{\text {b }} \mathbf{p}<0.05$ when compared with the low dose Marijuana (LMJ) treated group. Analysis was based on one way analysis of variance (ANOVA) and Tukey post hoc test

Key: Control- Control group; LMJ-Low dose Marijuana group; HMJ-High dose Marijuana group; HMJ+Vit C- High dose Marijuana + Vitamin C

Effects of Inhaled Marijuana and Vitamin C on Total Protein Levels in Male Wistar Rats

Total protein was significantly decreased $(\mathrm{p}<0.05)$ in the high dose Marijuana + vitamin $\mathrm{C}$ $(\mathrm{HMJ}+\mathrm{Vit} \mathrm{C})$ treated groups when compared with control group and within the other groups (Figure-4).

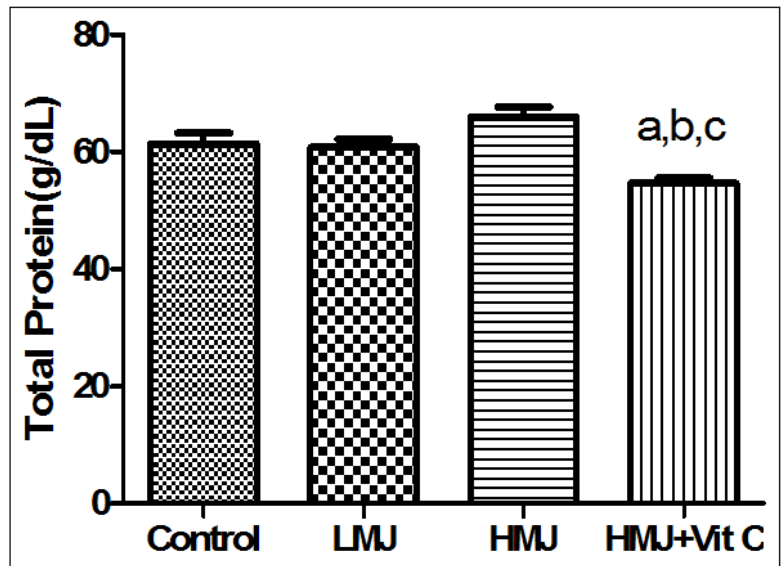

Fig-4: Graphical comparison of Total Protein level in male Wistar rats following the administration of Marijuana and vitamin $\mathbf{C}$ in the treated groups with the control group. Columns represent mean \pm SEM. $n=10{ }^{a} p<0.05$ when compared with the control group. ${ }^{b} \mathrm{p}<0.05$ when compared with the low dose Marijuana (LMJ) treated group. ${ }^{c} \mathbf{p}<0.05$ when compared with

the high dose Marijuana (HMJ) treated group. Analysis was

based on one way analysis of variance (ANOVA) and Tukey post hoc test

Key: Control- Control group; LMJ-Low dose Marijuana group; HMJ-High dose Marijuana group; HMJ+Vit C- High dose Marijuana + Vitamin C

Effects of Inhaled Marijuana and Vitamin C on total Cholesterol Levels in Male Wistar rats

Total cholesterol levels was significantly decreased $(\mathrm{p}<0.05)$ in the high dose Marijuana + vitamin $\mathrm{C}(\mathrm{HMJ}+\mathrm{Vit} \mathrm{C})$ treated groups when compared with control group (Figure-5).

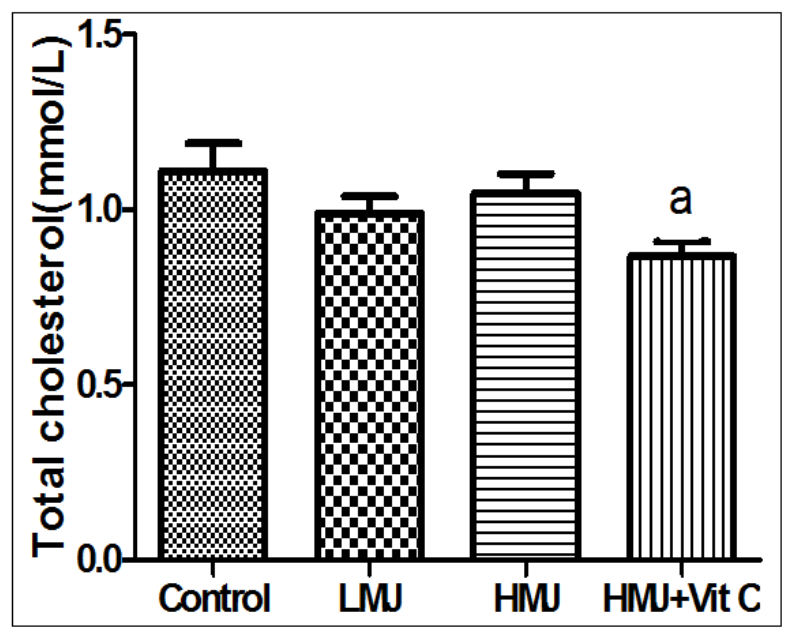

Fig-5: Graphical comparison of Total Cholesterol level in male Wistar rats following the administration of Marijuana and vitamin $\mathbf{C}$ in the treated groups with the control group. Columns represent mean \pm SEM. $n=10{ }^{a} p<0.05$ when compared with the control group. Analysis was based on one way analysis of variance (ANOVA) and Tukey post hoc test 
Key: Control- Control group; LMJ-Low dose Marijuana group; HMJ-High dose Marijuana group; HMJ+Vit C- High dose Marijuana + Vitamin C

Effects of Inhaled Marijuana and Vitamin C on High Density Lipoproteins Levels in Male Wistar Rats

High density lipoprotein levels was significantly decreased $(\mathrm{p}<0.05)$ in the high dose Marijuana + vitamin C (HMJ+Vit C) treated groups when compared with control group (Figure 6).

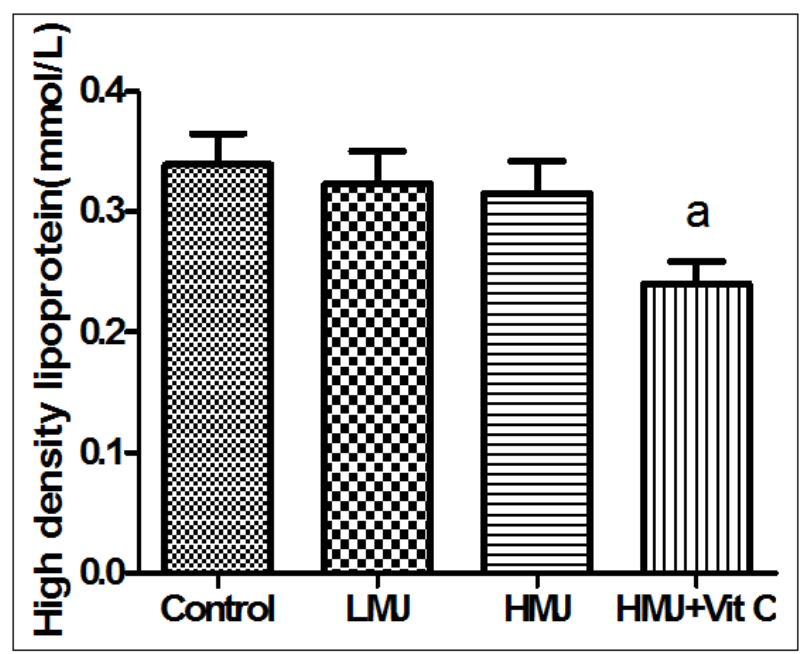

Fig-6: Graphical comparison of High Density Lipoprotein level in male Wistar rats following the administration of Marijuana and vitamin $\mathrm{C}$ in the treated groups with the control group. Columns represent mean \pm SEM. $n=10{ }^{\text {a }} p<0.05$ when compared with the control group. Analysis was based on one way analysis of variance (ANOVA) and Tukey post hoc test

Key: Control- Control group; LMJ-Low dose Marijuana group; HMJ-High dose Marijuana group; HMJ+Vit C- High dose Marijuana + Vitamin C

Effects of Inhaled Marijuana and Vitamin $\mathrm{C}$ on Triglycerides Levels in Male Wistar Rats

Triglycerides level was not significantly different in the low dose Marijuana (LMJ) treated group and high dose Marijuana + vitamin C (HMJ+Vit C) treated groups when compared with control group and within the groups (Figure-7).

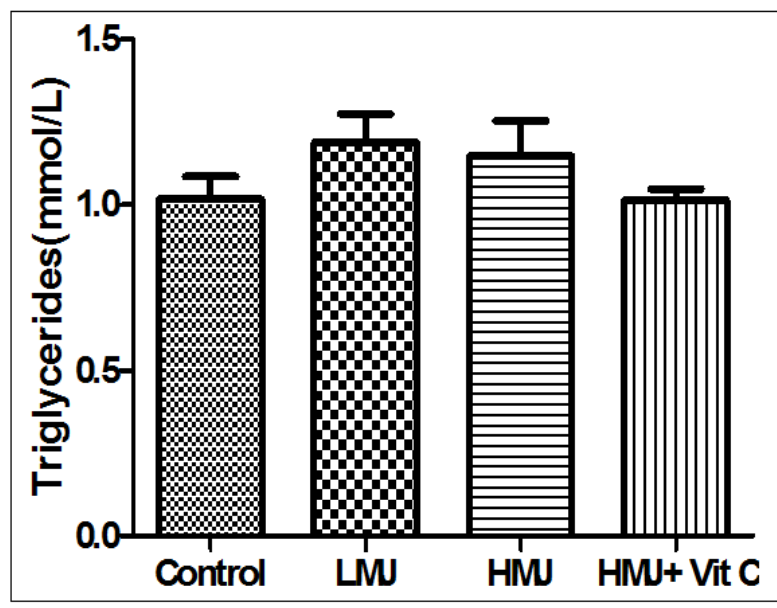

Fig-7: Graphical comparison of Triglyceride level in male Wistar rats following the administration of Marijuana and vitamin $\mathrm{C}$ in the treated groups with the control group. Columns represent mean \pm SEM. $n=10$. Analysis was based on one way analysis of variance (ANOVA) and Tukey post hoc test

Key: Control- Control group; LMJ-Low dose Marijuana group; HMJ-High dose Marijuana group; HMJ+Vit C- High dose Marijuana + Vitamin C

Effects of Inhaled Marijuana and Vitamin C on Low Density Lipoprotein levels in male Wistar rats

Low density lipoprotein level was significantly increased $(\mathrm{p}<0.05)$ in the high Marijuana + vitamin C $(\mathrm{HMJ}+\mathrm{Vit} \mathrm{C})$ treated groups when compared with control group (Figure 8).

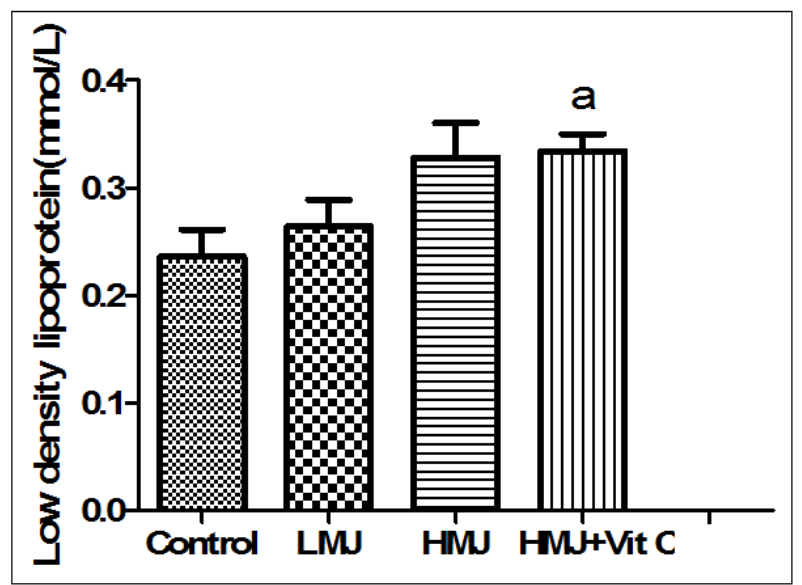

Fig-8: Graphical comparison of Low density Lipoprotein level in male Wistar rats following the administration of Marijuana and vitamin $\mathbf{C}$ in the treated groups with the control group. Columns represent mean \pm SEM. $n=10{ }^{a} p<0.05$ when compared with the control group. Analysis was based on one way analysis of variance (ANOVA) and Tukey post hoc test

Key: Control- Control group; LMJ-Low dose Marijuana group; HMJ-High dose Marijuana group; HMJ+Vit CHigh dose Marijuana + Vitamin C 


\section{DISCUSSION}

The antifertility potential of Marijuana observed in our recent study has attracted so much attention [1, 2]. Whether or not, it might cause other serious health defects in other body systems. As such, this study was setup to access the possible metabolic effects of marijuana in male rats.

Inhaled marijuana shows a deteriorating effect on serum protein levels (Figure 1, 2, 3). This result is in line with Irfans et al., 2017 [12] that cannabis abusers shows decrease serum albumin and total protein. Many literatures reveal that serum albumin and total protein are not significantly tainted by marijuana addiction. Irfan et al., [12] also revealed that cannabis abusers showed higher scores of Direct Bilirubin and this is also revealed in this current work as the levels in the experimental groups are significantly higher than the control groups. In contrast to Irfan et al., 2017 [12] and Okwari et al., 2014 [13], which showed that Total Bilirubin increase in marijuana abusers, a decrease level is observed in this study. The differences in the experimental setup may possibly be the reason for the contrasting result. Vitamin $\mathrm{c}$ has been observed to ameliorate the deteriorating effects specifically of Direct bilirubin. An additional decreasing effect by vitamin c was observed in Total bilirubin and Total protein suggesting that it has a direct impact on protein synthesis.

The observed alteration in the levels of serum proteins indicate the present of cannabinoid receptors in the liver and that inhaled marijuana interferes with protein synthesis, mobilization and clearance. Elevated levels of direct bilirubin may indicate liver damage, disease or enzyme inhibition major degradation pathways. Higher than normal levels of direct bilirubin in the blood may indicate that the liver is not clearing bilirubin properly. One common cause of elevated bilirubin is Gilbert's syndrome, a deficiency in an enzyme that helps break down bilirubin. This however, indicates that inhaled cannabis interferes with enzymes synthesis and its function. Albumin is synthesized in the liver, and low serum albumin may be indicative of defective synthetic pathway in the liver. Drugs are implicated in Hepatitis and marijuana; an illicit drug could be one of them. Low albumin observed in this study is an indication that marijuana has serious deteriorating effects on the liver possibly leading to inflammation. Total Protein level was unchanged in the low dose group compared to control, slightly elevated in high dose group and decreased in Vitamin C group. This is probably due to contribution of the globulin fraction. Inhalational exposure may likely have on the globulin fraction. This could not be ascertained in this study due to various limitations.

The in vivo cardiovascular effects of cannabinoids are complex, with both increase and decrease in blood pressure being reported [14]. As reported by different research groups, smoking increases the concentration of serum total cholesterol, triglycerides, LDL cholesterol and decreases the levels of HDL cholesterol [15]. This is in consonance with this current study. Major component of total cholesterol is LDL cholesterol which is directly related to coronary artery disease (CAD) has been reported to be increased by cannabis use [16].

Cannabis use was also said to be associated with vascular conditions that increase the risks of myocardial infarction, stroke, and transient ischemic attacks during cannabis intoxication [17]. In all of the above named disease conditions, high lipid deposition which is observed in this study is known to be one of the risk factor. Smoking, in different forms has been reported to be a major risk factor for atherosclerosis and coronary heart disease [18] in which high lipid is implicated as well. Marijuana use can also cause an increase in the risk of myocardial infarction in an hour after use, and provokes angina (inflammatory affection of the throat or faces especial such that tends to produce suffocation and choking, it can be marked by chest pain) in patients with heart disease [19]. While some data suggest marijuana use to confer cardio metabolic benefits such as reductions in Low Density Lipoprotein (LDL) [20], this current studies and some other studies show that marijuana users have lower plasma High Density Lipoprotein (HDL), which are important risk factors for cardiovascular disease [21]. Cannabis may produce adverse effects on the cardiovascular system, because cannabis and THC ( $\Delta 9$ tetrahydrocannabiol) cause a dose-dependent increase in heart rate [19]. Some studies show that cannabis users have a lower Serum High Density Lipoprotein (HDL), which are important risk factors for cardiovascular disease [21]. High levels of triglycerides and low levels of HDL has shown in this study has been reported to raise the risk of heart disease.

The total cholesterol levels in this study were not significantly altered possibly due to the balance between the decrease HDL and increase LDL levels. Vitamin c was able to reduce the effect on triglycerides. It was observed to decrease the levels of total cholesterol and HDL but has no effect on LDL.

\section{CONCLUSION}

This study has shown that inhaled Marijuana negatively affected various liver metabolic pathways leading to decline in albumin levels; elevated Bilirubin and lipid levels.

Co-administration of oral Vitamin $\mathrm{C}$ was found to lower serum Bilirubin levels. Levels of total Cholesterol, High Density Lipoproteins and Tryglycerides were also lowered in rats treated with Vitamin C. It is possible that the use of Vitamin C may be beneficial in individuals at risk of cardiovascular diseases. 


\section{REFERENCES}

1. Udokang, N. E., \& Udom, U. G. (2019). Antifertility Effect of Inhaled Cannabis Sativa on Male Wistar Rats. American Journal of Health Research, 7(2):1-7.

2. Udokang, N. E., \& Udom, U. G. (2019). Vitamin C Ameliorates the Antifertility Effects of Inhaled Marijuana in Rats. Science Journal of Public Health, 7(5):140-150.

3. Bhattacharyya, S., Morrison, P. D., Fusar-Poli, P., Martin- Santos, R., Borgwardt, S., Winton-Brown, T., Nosarti, C., O' Carroll, C. M., Seal, M., Allen, P., Mehta, M. A., Stone, J. M., Tunstall, N., Giampietro, V., Kapur, S., Murray, R. M., Zuardi, A. W., Crippa, J. A., Atakan, Z., \& McGuire, P. K. (2010). Opposite effects of delta-9tetrahydrocannabinol and cannabidiol on human brain function and psychopathology. Neuropsychopharmacology, 35(3): 764-774.

4. Devane, W., Dysarz, F., Johnson, M., Melvin, L., \& Howlett, A. (1988) Determination and characterization of a cannabinoid receptor in rat brain. Molecular Pharmacology, 34: 605-613.

5. Munro, S., Thomas, K., \& Abu-Shaar, M. (1993). Molecular characterization of a peripheral receptor for cannabinoids. Nature, 365: 61-65.

6. Russo, E., \& Guy, G. (2006). A tale of two cannabinoids: the therapeutic rationale for combining tetrahydrocannabinol andcannabidiol. Medical Hypotheses. 66: 234-246.

7. Pagotto, U., Marsicano, G., Cota, D., Lutz, B., \& Pasquali, R. (2006). The emerging role of the endocannabinoid system in endocrine regulation and energy balance. Endocrine Reviews, 27: 73100.

8. Pertwee, R. (2006). The pharmacology of cannabinoid receptors and their ligands: an overview. International Journal of Obesity (London), 30: S13-S18.

9. Izzo, A. (2004) Cannabinoids and intestinal motility: welcome to $\mathrm{CB} 2$ receptors. British Journal of Pharmacology, 142: 1201-1202.

10. George, R. K. (2009). Biochemistry Laboratory. Philadelphia www.jbc.org.
11. Bjorston, A. R., Crankshaw, D. P., Morgan, D. J., \& Prideaux, P. R. (2007). Clinical Chemistry. Department of surgery, Royal Malbourne Hospital, University of Melbourne, Victoria, 3050.

12. Irfan, A. W., Muzafer, A. K., \& Bhupinder, S. (2017). Effect of Cannabis Abuse and Ezymatic Alterations to Endorse Liver Dysfunctions. Global Journal of Addiction \& Rehabilitation Medicine. 3(1): 555605.

13. Okwari, O. O., Emerole, C .G, Dasofunjo, K, Alagwu, E. A, Olatunji, T. L and Osim, E. E. (2014). Impact of repeated administration of Cannabis sativa on some biochemical parameters in albino rats. IOSR Journal of Pharmacy and Biological Sciences. 9(1): 55-57.

14. Stark, P., \& Dews, P. B. (1980). Cannabinoids II. Cardiovascular effects. Journal. Pharmacology Experimental Therapy. 214: 131-138.

15. Adam, D. G., Heather, M., Timothy, B., \& James, H. (2011). Effects of smoking and smoking cessation on lipids and lipoproteins: outcomes from a randomized clinical trial. American Heart Journal. 16: 145-151.

16. Brousseau, M. E., \& Schaefer, E. J. (2000). Diet and Coronary Heart Disease: Clinical Trials on Current Atherosclerosis. 2: 487-493.

17. Thomas, G., Kloner, R. A., \& Rezkalla, S. (2014). Adverse cardiovascular, cerebrovascular, and peripheral vascular effects of marijuana inhalation: what cardiologists need to know. American Journal Cardiology. 113(1): 187-190.

18. Fagerström, K. (2002). The epidemiology of smoking: health consequences and benefits of cessation. Drugs: 62(2):1-9.

19. Hall, W., \& Degenhard, L. (2009). Adverse health effects of non-medical cannabis use. Lancet: 374:1383-1391.

20. Penner, E. A., Buettner, H., \& Mittleman, M. A. (2013). The impact of marijuana use on glucose, insulin, and insulin resistance among US adults. American Journal of Medicine: 126(7):583-589.

21. Muniyappa, R., Sable, S., Ouwerkerk, R., Mari, A., Gharib, A. M., \& Walter, M. (2013). Metabolic effects of chronic cannabis smoking. Diabetes Care: 36(8):2415-2422. 